\title{
Perbandingan Pengaruh Aktivitas Lompat Engklek Dengan Aktivitas Lompat Tali Terhadap Kemampuan Lompat Jauh
}

\author{
*Gumilar Dwi Wardani ${ }^{1}$ dan Agus Mahendra ${ }^{1}$ \\ ${ }^{1}$ Program Studi Pendidikan Guru Sekolah Dasar Pendidikan Jasmani, \\ Fakultas Pendidikan Olahraga dan Kesehatan, Universitas Pendidikan Indonesia \\ email : gumilardwiwardani@gmail.com
}

\begin{abstract}
Abstrak
Tujuan dari penelitian ini adalah untuk mengetahui pengaruh aktivitas lompat engklek (hopping) dan aktivitas lompat tali (skipping rope) terhadap kemampuan lompat jauh, untuk digunakan sebagai alternatif pembelajaran lompat jauh manakala persoalan dukungan sarana di sekolah masih terbatas. Metode penelitian ini menggunakan metode eksperimen dengan desain two group pretest-posttest design. Populasi dari penelitian ini adalah siswa kelas V SDN Gegerkalong KPAD sebanyak 111 siswa dan sampel sebanyak 30 siswa yang diambil menggunakan teknik simple random sampling. Instrumen tes yang digunakan dalam penelitian ini adalah tes lompat jauh. Berdasarkan hasil penelitian, data yang diperoleh berdistribusi tidak normal tetapi homogen. Analisis statistik pada penelitian ini menggunakan uji Wilcoxon. Hasil pengujian menunjukan bahwa pembelajaran aktivitas lompat engklek memberikan pengaruh yang signifikan terhadap kemampuan lompat jauh sedangkan pembelajaran aktivitas lompat tali tidak memberikan pengaruh yang signifikan terhadap kemampuan lompat jauh. Dengan demikian, pembelajaran aktivitas lompat engklek dipandang menjadi alternatif yang lebih baik dibandingkan dengan pembelajaran aktivitas lompat tali dalam meningkatkan kemampuan lompat jauh siswa.
\end{abstract}

Kata kunci: Lompat Engklek, Lompat Tali, Lompat Jauh.

*Gumilar Dwi Wardani adalah lulusan Program Studi PGSD Penjas, Departemen Pendidikan Olahraga, Fakultas Pendidikan Olahraga dan Kesehatan, Universitas Pendidikan Indonesia. 


\title{
The Comparison Effect between a Single Leg Hopping and Jumping Rope Activities on the Long Jump Ability
}

\begin{abstract}
The purpose of this research is to investigate the effect of engklek (singleleg hop) and skipping rope activity on long jumping learning proses. These two activities are expected to be implemented when the learning prosses can not be supported by the availability of jumping facilities in schools, as an alternative for teachers to improving children's jumping ability. The research method to be used is experimental method with a two-group pretest-posttest design. The population of this research is grade $V$ students at Gegerkalong KPAD elementary schools, and 30 students are taken as sample with using simple random sampling technique. The instrument to be occupied in this research is long jumping skill test. The collected data was not normally distributed but basically homogenous. For that reason, the statistical analysis to be used is the wilcoxon test. The results showed that the engklek jumping activity gave a significant effect on the long jumping ability while the jumping-rope gave the opposit result. It is concluded that giving children the engklek activity to improve long jumping ability is more beneficial than giving children jumping rope activity.
\end{abstract}

Keyword: Single Leg Hop, Jumping Rope, Long Jump.

\section{PENDAHULUAN}

Sekolah merupakan salah satu wadah bagi terlaksananya proses pendidikan, yaitu tempat berlangsungnya proses belajar dan mengajar. Pembelajaran di sekolah terdiri dari berbagai macam disiplin ilmu, dan salah satunya adalah pendidikan jasmani. Pendidikan jasmani adalah proses pendidikan yang memanfaatkan aktivitas jasmani, permainan atau olahraga yang terpilih untuk mencapai tujuan pendidikan (Mahendra, 2015). Sejalan dengan itu, penulis berpendapat bahwa pendidikan jasmani adalah proses pembelajaran yang menggunakan aktivitas fisik atau olahraga untuk mencapai tujuan pendidikan yang menyeluruh yaitu aspek kognitif, afektif dan psikomotor. Pendidikan jasmani memberikan kesempatan kepada anak untuk mempelajari berbagai kegiatan yang 
membina sekaligus mengembangkan potensi anak, baik dalam aspek fisik, mental, sosial, emosional dan moral (Mahendra, 2015).

Atletik merupakan salah satu cabang olahraga yang masuk ke dalam ruang lingkup permainan dan olahraga di dalam mata pelajaran PJOK. Atletik memiliki nomo-nomor lomba induk yaitu nomor jalan, lari, lompat dan lempar. Atas dasar itu pula cabang olahraga atletik ini sering disebut "ibu olahraga" karena terdiri dari gerak dasar manusia yang melibatkan gerakan jalan, lari, lompat dan lempar. Dengan keempat gerak dasar tersebut, atletik menjadi cabor yang juga amat dianjurkan untuk dipelajari di sekolah, karena akan memberikan pengalaman gerak yang sangat luas kepada siswa sebagai bekal untuk kehidupan anak di masa-masa selanjutnya.

Dalam proses pembelajaran atletik khususnya pembelajaran lompat jauh, pada umumnya masih banyak sekolah di perkotaan yang tidak mempunyai fasilitas atau tempat lompat jauh. Hal itu menyebabkan pembelajaran lompat jauh menjadi sulit untuk dilaksanakan. Oleh karena itu siswa tidak memiliki kemampuan dasar yang cukup baik dalam lompat jauh. Adapun kemampuan dasar lompat jauh dibagi menjadi empat tahapan atau empat fase dimulai dari fase awalan, fase tolakan, fase melayang, dan fase mendarat. Pada umumnya unsur utama penyebab kurangnya pencapaian lompat jauh pada siswa sekolah dasar adalah saat melakukan awalan dan tolakan. Faktor penyebab utama adalah kurangnya kekuatan otot tungkai dan penguasaan teknik lompat jauh khususnya pada saat menolak. Tolakan adalah salah satu unsur utama yang menyebabkan pencapaian lompat jauh kurang optimal. 
Oleh karena itu, perlu adanya upaya pendekatan serta langkah-langkah untuk perbaikan pembelajaran lompat jauh. Guru juga dituntut untuk mengembangkan kreatifitasnya dalam proses mengajar sehingga pembelajaran tidak menimbulkan rasa jenuh pada siswa yang menyebabkan hasil pembelajaran siswa menjadi kurang optimal. Maka seorang guru harus pandai memilih metode dan variasi (Mahendra, 2007) yang tepat untuk diberikan kepada siswa sehingga memudahkan siswa dalam meningkatkan keterampilan gerak dasar dalam kemampuan lompat jauh. Dalam proses pembelajaran pendidikan jasmani, tidak semua guru penjas menyadari pentingnya pendidikan jasmani (Mahendra, 2014).

Berdasarkan uraian tersebut, penulis tertarik untuk menerapkan alternatif pembelajaran gerak dasar lompat jauh (Mahendra, 2015) melalui aktivitas jasmani sederhana agar kemampuan siswa dalam melakukan lompat jauh menjadi lebih baik. Alternatif pembelajaran yang bisa diterapkan dalam pembelajaran gerak dasar (Mahendra, 2017) lompat jauh adalah aktivitas lompat engklek dan aktivitas lompat tali. Lompat engklek merupakan permainan melompati rintangan berupa suatu benda. Benda yang dapat digunakan untuk menjadi rintangan dalam permainan engklek bisa berupa benda sederhana seperti kardus bekas, ban bekas dan lain-lain. Lompat tali merupakan permainan melompati tali yang dibentangkan dengan ketinggian tertentu. Adapun lompat tali skipping merupakan permainan melompat menggunakan bantuan tali yang diputar atau digerakan sebagai rintangan dari lompatan yang dilakukan dengan menggunakan kedua tangan kita sebagai porosnya (Mahendra, 2015). Sama seperti lompat engklek, media permainan lompat tali skipping juga sangat sederhana bisa 
berupa tali karet yang disusun sedemikian rupa membentuk tali karet yang memiliki panjang tertentu, maksudnya panjang tali karet yang dibuat disesuaikan dengan tinggi penggunanya, semakin tinggi penggunanya maka tali karet yang disusun juga akan semakin panjang. Kedua permainan ini mempunyai kesamaan dalam inti permainannya yaitu melompati suatu rintangan tertentu. Berdasarkan latar belakang tersebut, penulis tertarik untuk meneliti dan menguji bagaimana pengaruh kedua aktivitas tersebut terhadap lompat jauh dan aktivitas manakah yang lebih efektif terhadap kemampuan lompat jauh siswa SD.

\section{METODE}

Penelitian menggunakan pendekatan kuantitatif dengan menggunakan metode eksperimen dan desain pretest-posttest group design. Penelitian ini dilakukan kepada 30 sampel siswa kelas V SDN Gegerkalong KPAD Bandung, teknik pengambilan sampel pada penelitian ini menggunakan probability sampling dengan teknik simple random sampling. Kemudian sampel dibagi kedalam dua kelompok dengan cara pengundian. Adapun teknik pengumpulan data hasil penelitian didapatkan dari instrumen penelitian berupa tes lompat jauh. Instrumen yang digunakan dalam penelitian ini adalah tes lompat jauh yang diberikan kepada siswa sebanyak tiga kali kesempatan.

\section{HASIL DAN PEMBAHASAN}

Dalam penelitian ini, berdasarkan hasil penelitian, pengolahan dan analisis dari seluruh data yang terkumpul, maka hasilnya memberikan jawaban terhadap permasalahan yang diajukan dalam penelitian. Setelah kedua sampel eksperimen diberikan treatment atau perlakuan dimana kelompok 
aktivitas lompat engklek mendapatkan perlakuan berupa aktivitas lompat engklek dalam proses pembelajaran menghasilkan rata-rata skor tes awal lompat jauh kelompok aktivitas lompat engklek adalah sebesar 243,1 dan rata-rata skor tes akhir adalah sebesar 251,1. Sedangkan kelompok aktivitas lompat tali diberikan treatment atau perlakuan berupa aktivitas lompat tali dalam proses pembelajaran menghasilkan rata-rata skor tes awal lompat jauh mendapatkan skor sebesar 248,5 dan rata-rata skor tes akhir sebesar 249,3.

Berdasarkan uraian di atas, dapat diketahui bahwa kelompok aktivitas lompat engklek mengalami peningkatan rata-rata yang lebih baik dibandingkan dengan kelompok aktivitas lompat tali. Hal itu menjelaskan bahwa pembelajaran aktivitas lompat engklek memberikan pengaruh yang lebih signifikan dibandingkan dengan pengaruh aktivitas lompat tali terhadap kemampuan lompat jauh. Hal tersebut juga dapat dilihat dari selisih (gain) rata-rata antara skor tes awal dengan skor tes akhir dimana pada kelompok aktivitas lompat engklek menghasilkan rata-rata peningkatan sebesar 8, sedangkan pada kelompok aktivitas lompat tali menghasilkan rata-rata peningkatan sebesar 0,7 .

Pemberian alternatif pembelajaran berupa aktivitas lompat engklek dan aktivitas lompat tali cukup membantu dan berpengaruh terhadap peningkatan kemampuan lompat jauh, dengan demikian pembelajaran aktivitas lompat engklek dan aktivitas lompat tali merupakan alternatif pembelajaran yang tepat yang dapat diberikan untuk meningkatkan kemampuan lompat jauh siswa apabila sarana dan prasarana di sekolah kurang memadai. Dalam hal ini, pembelajaran aktivitas lompat engklek 
lebih memberikan pengaruh yang lebih signifikan dikarenakan dalam proses pembelajaran siswa melakukan gerakan awalan, tolakan, melayang di udara serta mendarat yang merupakan gerakan dasar dalam lompat jauh. Selain itu, pada setiap pelaksanaan aktivitas lompat engklek, siswa diharuskan melakukan awalan untuk mendapatkan momentum kecepatan horizontal dan melakukan tolakan untuk mengubah momentum kecepatan horizontal menjadi kecepatan vertikal dalam melewati rintangan dengan optimal. Disamping itu, pembelajaran aktivitas lompat tali pada dasarnya juga berpengaruh terhadap peningkatan kemampuan lompat jauh siswa namun tidak memberikan pengaruh yang signifikan seperti aktivitas lompat engklek.

Berdasarkan uraian tersebut, pada dasarnya kedua alternatif pembelajaran baik itu pembelajaran aktivitas lompat engklek maupun lompat tali telah memberikan pengaruh terhadap peningkatan kemampuan lompat jauh siswa. Dari hal tersebut dapaat dibuktikan bahwa kedua alternatif pembelajaran dapat merangsang serta menguatkan kekuatan otot tungkai anak didik. Dengan bermain lompat tali motorik kasar akan terstimulasi sehingga secara fisik anak jadi lebih terampil, karena bisa belajar cara dan teknik melompat yang dalam permainan ini memangmemerlukan keterampilan tersendiri. Lama-kelamaan, bila sering dilakukan, anak dapat tumbuh menjadi cekatan, tangkas dan dinamis. Otot-ototnya pun padat dan berisi, kuat serta terlatih (Anggani, 2013). Selain itu, pengaruh lompat tali terhadap tubuh salah satunya adalah membuat kaki dan pinggul menjadi lebih kuat (Young, 2005). Dari penelitian terdahulu, Susilo (2008) menunjukan bahwa ada pengaruh yang segnifikan latihan lompat jauh menggunakan kotak kardus dan bilah terhadap kemampuan lompat jauh 
gaya jongkok. Selanjutnya, Kurniawan (2012) menunjukan bahwa melalui pendekatan bermain lompat tali meningkatkan hasil belajar lompat jauh siswa. Berdasarkan peneletian relevan terdahulu yang telah dilakukan, dapat dikethui bahwa aktivitas lompat menggunakan media baik itu kardus maupun lompat tali keduanya mampu meningkatkan hasil belajar lompat jauh.

Dalam hal ini pembelajaran aktivitas lompat engklek memberikan pengaruh yang signifikan dibandingkan dengan pembelajaran aktivitas lompat tali. Berdasarkan hasil temuan pada penelitian ini, kedua alternatif pembelajaran dapat diterapkan baik salah satu maupun keduanya secara langsung untuk meningkatkan kemampuan lompat jauh sebagai variasi dari pembelajaran lompat jauh untuk mengatasi kurangnya sarana prasarana lompat jauh serta untuk mengemas pembelajaran lompat jauh menjadi lebih menarik. Dalam hal ini, berdasarkan penelitian yang telah dilakukan, penulis menyarankan untuk lebih mengoptimalkan alternatif pembelajaran aktivitas lompat engklek untuk meningkatkan kemampuan lompat jauh agar pencapian kemampuan lompat jauh siswa menjadi lebih optimal.

\section{KESIMPULAN}

1. Pembelajaran aktivitas lompat engklek memberikan pengaruh yang signifikan terhadap kemampuan lompat jauh.

2. Pembelajaran aktivitas lompat tali tidak memberikan pengaruh yang signifikan terhadap kemampuan lompat jauh. 
3. Pembelajaran aktivitas lompat engklek memberikan pengaruh yang signifikan dibandingkan dengan pembelajaran aktivitas lompat tali terhadap kemampuan lompat jauh.

\section{IMPLIKASI}

Hasil penelitian mengenai perbandingan pengaruh alternatif pembelajaran aktivitas lompat engklek dan lompat tali menyatakan bahwa keduanya memberikan pengaruh terhadap kemampuan lompat jauh, dengan rincian bahwa aktvitas engklek telah memberikan pengaruh terhadap peningkatan kemampuan lompat jauh sebesar $8 \mathrm{~cm}$, sedangkan aktivitas lompat tali memberikan pengaruh peningkatan terhadap kemampuan lompat jauh sebesar $0,7 \mathrm{~cm}$. Berdasarkan hal tersebut, dalam hal ini alternatif pembelajaran aktivitas lompat engklek memberikan pengaruh yang lebih signifikan terhadap kemampuan lompat jauh dibandingkan dengan aktivitas lompat tali.

Dilihat dari fakta ini, alternatif pembelajaran dengan pemberian aktivitas yang terkait dengan peningkatan komponen gerak utama lompat jauh memang diperlukan untuk mengatasi permasalahan kurangnya sarana dan prasarana yang mendukung dalam proses pembelajaran. Oleh karena itu guru dapat selalu berupaya mencari alternatif-alternatif pembelajaran untuk mengatasi permasalahan kurangnya sarana dan prasarana dalam cabang atau pembelajaran apapun. Namun demikian, pembelajaran lompat jauh pada dasarnya merupakan upaya untuk meningkatkan jarak lompatan yang dihasilkan dari kemampuan menolak serta besaran momentum horizontal dari awalan. Tetapi di luar itu, kemampuan lompat jauh juga ditentukan oleh fase melayang serta fase mendarat. Dalam hal ini, 
alternatif pembelajaran yang telah diberikan pada dasarnya hanya mengoptimalkan kemampuan besaran momentum horizontal yang didapatkan dari awalan serta kemampuan besaran momentum vertikal yang didapatkan pada saat menolak. Oleh karena itu, teknik dasar melayang serta mendarat dalam hal ini tidak dilatih secara optimal.

Berdasarkan hal tersebut, agar kemampuan lompat jauh menjadi lebih optimal, pembelejaran lompat jauh yang diberikan idealnya harus menggunakan pendekatan pembelajaran yang secara utuh mempelajari semua teknik dasar dalam lompat jauh dari mulai fase awalan, tolakan, melayang dan mendarat. Disamping itu, alternatif pembelajaran lompat engklek dan lompat tali juga semata bisa dikatakan sebagai variasi dari proses pembelejaran lompat jauh guna menjadikan otot tungkai siswa menjadi lebih kuat serta membuat siswa lebih bugar. Selain itu, dengan berbagai variasi gerak yang terdapat pada kedua alternatif pembelajaran tersebut, proses pembelejaran lompat jauh dapat dikemas dengan menarik sehingga tidak membuat siswa bosan dan menjadikan siswa lebih menyukai aktivitas atletik.

\section{REKOMENDASI}

Bagi para guru pendidikan jasmani, alternatif pembelajaran aktivitas lompat engklek dapat diterapkan untuk meningkatkan kemampuan lompat jauh siswa. Bagi siswa penerapan alternatif pembelajaran aktivitas lompat engklek dapat dijadikan alternatif pembelajaran yang menyenangkan untuk meningkatkan kemampuan lompat jauh. Bagi peneliti selanjutnya, disarankan untuk mencari alternatif pembelajaran lain yang memberikan 
pengaruh yang lebih signifikan terhadap kemampuan lompat jauh agar pencapaian kemampuan siswa dalam lompat jauh menjadi lebih optimal. 


\section{DAFTAR PUSTAKA}

Direktori File UPI. (2012). Pendidikan Tentang Aktivitas Jasmani. Bandung: FPOK UPI.

Djumaidar, W, A. (2004). Belajar Berlatih Gerak-Gerak Dasar Atletik Dalam Bermain. Jakarta. PT Rajagrafindo Persada.

KN, Darajat, J., Abduljabar, B. (2013). Aplikasi Statistika Dalam Penjas. Bandung: Bintang Warliartika.

Mahendra, Agus. (2007). Modul Teori Belajar Mengajar Motorik. Bandung: FPOK UPI.

Mahendra, Agus. (2015a). Filsafat Pendidikan Jasmani: Dasar-dasar Pembelajaran Penjas di Sekolah Dasar. Bandung: CV. Bintang WarliArtika.

Mahendra, Agus. (2015b). Permainan Anak dan Permainan Tradisional. Bandung: CV. Bintang WarliArtika.

Mahendra, Agus. (2015c). Pembelajaran Musik dan Gerak: Dasar Pengembangan Aktivitas Ritmik di Sekolah Dasar. Bandung: CV. Bintang WarliArtika.

Mahendra, Agus. (2017). Model Pendidikan Gerak Implementasi Pendidikan Jasmani di Sekolah Dasar. Modul. Bandung: FPOK-UPI.

Mahendra, Agus. (2014). "Telaah Kritis terhadap Program Pendidikan Guru Pendidikan Jasmani (PGPJ) di Indonesia." Volume 4 (2), Desember 2014. ATIKAN. Jurnal Kajian Pendidikan (Journal for Educational Studies).

Menteri Pendidikan Nasional. (2014). Peraturan Menteri Pendidikan Nasional Republik Indonesia No. 57 Tahun 2014 Tentang Pelaksanaan. Jakarta: PERMENDIKNAS

M, Husna, A. (2009). 100+ Permainan Tradisional Indonesia untuk Kreativitas,

Ketangkasan, dan Keakraban. Yogyakarta; C.V ANDI OFFSET

Rasyidin, W. Dkk. (2014). Landasan Pendidikan. Bansung: Sub Koordinator MKDP Landasan Pendidikan Jurusan Pedagogik FIP UPI

Rohmah, O. \& Carsiwan. (2013). Sport History and Philosophy. Bandung: FPOK UPI.

Sidik, Zafar, D. (2010). Mengajar dan Melatih Atletik. Bandung: PT REMAJA ROSDAKARYA.

Sidik. \& Komarudin. (2009). Pedoman Mengajar dan Melatih Atletik. Bandung: FPOK UPI. 
Subroto, T., Yudiana, Y., \& Hidayat, Y. (2016). Penulisan Penelitian Tindakan

Kelas Dalam Pendidikan Jasmani, Olahraga, dan Kesehatan. Bandung: FPOK UPI.

Sugiyono. (2016). Metode Penelitian Pendidikan. Bandung: CV. ALFABETA.

Syarifuddin, A. \& Muhadi. (1992/1993). Pendidikan Jasmani Dan Kesehatan.

Jakarta: Departemen Pendidikan Dan Kebudayaan Direktorat Jenderal Pendidikan Tinggi Proyek Pembinaan Tenaga Kependidikan

Tarigan, Beltasar, F. (2012). Optimalisasi Pendidikan Jasmani dan Olahraga Berlandaskan Ilmu Faal Olahraga. Bandung: eidos.

Universitas Pendidikan Indonesia. (2015). Peraturan rektor tentang pedoman karya tulis ilmiah upi tahun akademik 2015. Bandung: upi

Wiarto, Giri. (2013). ATLETIK. Yogyakarta: Graha Ilmu.

Yudy,. Alit . (2014). Bermain Atletik. Bandung: FPOK UPI.

Kurniawan, F. (2012). Upaya Meningkatkan Hasil Belajar Lompat Jauh Melalui

Pendekatan Bermain Lompat Tali Kelas V di SD Negeri I Kecitran Purwareja Klampok Banjarnegara Jawa Tengah. (Skripsi). Fakultas Ilmu Keolahragaan, UNY, Yogyakarta.

Nurjaya, D.R. \& Mulyana, R. (2010). Pendidikan Jasmani dan Olahraga. Jurnal: Mengembangkan Perilaku Asosiatif Siswa SD Melalui Penerapan Pendekatan Bermain Dalam Konteks Pembelajaran Penjas, 1 (2), hlm. 5261.

Paputungan, S. (2013). Pengaruh latihan skipping terhadap tinggi loncatan vertical pada pemain bola voli putera di mts negeri 1 telaga biru kabupaten gorontalo. (Skripsi). Sekolah Sarjana. Universitas Negeri Gorontalo, Gorontalo.

Pratiwi, Y. (2014). Jurnal Penelitian PAUDIA. Jurnal: Upaya Meningkatkan Kemampuan Motorik Kasar (Keseimbangan Tubuh) Anak Melalui Permainan Tradisional Engklek Di Kelompok b, hlm. 18-39.

Priyono, Ali. (2015). Pengaruh model pembelajaran inkuiri terhadap hasil belajar keterampilan gerak dasar lompat jauh. (Tesis). Sekolah Pascasarjana, Universitas Pendidikan Indonesia, Bandung.

Young, Eun, C. (2005). Fun Jump Rope. South Korea. 